\title{
Enhancing global vaccine pharmacovigilance: Proof-of-concept study on aseptic meningitis and immune thrombocytopenic purpura following measles-mumps containing vaccination
}

\author{
Silvia Perez-Vilar ${ }^{\mathrm{a}, \mathrm{b}, *}$, Daniel Weibel ${ }^{\mathrm{a}, \mathrm{c}}$, Miriam Sturkenboom ${ }^{\mathrm{a}, \mathrm{c}}$, Steven Black ${ }^{\mathrm{c}, \mathrm{d}}$, Christine Maure ${ }^{\mathrm{e}}$, \\ Jose Luis Castro ${ }^{\mathrm{f}}$, Pamela Bravo-Alcántara ${ }^{\mathrm{g}}$, Caitlin N. Dodd ${ }^{\mathrm{a}}$, Silvana A. Romio ${ }^{\mathrm{a}, \mathrm{h}}$, Maria de Ridder ${ }^{\mathrm{a}}$, \\ Swabra Nakato ${ }^{a}$, Helvert Felipe Molina-León ${ }^{i}$, Varalakshmi Elango ${ }^{j}$, Patrick L.F. Zuber ${ }^{\mathrm{e}}$, the WHO Global \\ Vaccine Safety-Multi Country Collaboration ${ }^{1}$ \\ a Department of Medical Informatics, Erasmus University Medical Center, Rotterdam, The Netherlands \\ ${ }^{\mathrm{b}}$ Vaccine Research Unit, Fundación para el Fomento de la Investigación Sanitaria y Biomédica de la Comunitat Valenciana, FISABIO, Valencia, Spain \\ ${ }^{\mathrm{c}}$ VACCINE.GRID Foundation, Basel, Switzerland \\ ${ }^{\mathrm{d}}$ Center for Global Child Health, Cincinnati Children's Hospital Medical Center, Cincinnati, OH, United States \\ ${ }^{\mathrm{e}}$ Department of Essential Medicines and Health Products, World Health Organization, Geneva, Switzerland \\ ${ }^{\mathrm{f}}$ Unit of Medicines and Health Technologies, Department of Health Systems and Services, Pan American Health Organization (PAHO/WHO), Washington DC, DC, United States

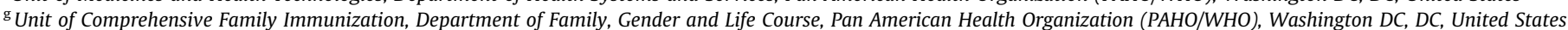 \\ ${ }^{\mathrm{h}}$ Department of Statistics and Quantitative Methods, University of Milan-Bicocca, Milan, Italy \\ i International Professional Consultant, Pan American Health Organization (PAHO/WHO), Washington DC, DC, United States \\ ${ }^{\mathrm{j} I n t e r n a t i o n a l ~ P r o f e s s i o n a l ~ C o n s u l t a n t, ~ W o r l d ~ H e a l t h ~ O r g a n i z a t i o n, ~ G e n e v a, ~ S w i t z e r l a n d ~}$
}

\section{A R T I C L E I N F O}

Article history:

Received 25 March 2017

Received in revised form 2 May 2017

Accepted 4 May 2017

Available online 27 May 2017

Keywords:

Post-marketing surveillance

Vaccine safety

Global Vaccine Safety Initiative (GVSI)

Adverse events following immunization

(AEFI)

\begin{abstract}
A B S T R A C T
New vaccines designed to prevent diseases endemic in low and middle-income countries (LMICs) are now being introduced without prior record of utilization in countries with robust pharmacovigilance systems. To address this deficit, our objective was to demonstrate feasibility of an international hospitalbased network for the assessment of potential epidemiological associations between serious and rare adverse events and vaccines in any setting. This was done through a proof-of-concept evaluation of the risk of immune thrombocytopenic purpura (ITP) and aseptic meningitis (AM) following administration of the first dose of measles-mumps-containing vaccines using the self-controlled risk interval method in the primary analysis. The World Health Organization (WHO) selected 26 sentinel sites ( 49 hospitals) distributed in 16 countries of the six WHO regions. Incidence rate ratios (IRR) of 5.0 (95\% CI: 2.59.7) for ITP following first dose of measles-containing vaccinations, and of 10.9 (95\% CI: 4.2-27.8) for AM following mumps-containing vaccinations were found. The strain-specific analyses showed significantly elevated ITP risk for measles vaccines containing Schwarz (IRR: 20.7; 95\% CI: 2.7-157.6), EdmonstonZagreb (IRR: 11.1; 95\% CI: 1.4-90.3), and Enders'Edmonston (IRR: 8.5; 95\% CI: 1.9-38.1) strains. A significantly elevated AM risk for vaccines containing the Leningrad-Zagreb mumps strain (IRR: 10.8; $95 \% \mathrm{CI}$ : 1.3-87.4) was also found. This proof-of-concept study has shown, for the first time, that an international hospital-based network for the investigation of rare vaccine adverse events, using common standardized procedures and with high participation of LMICs, is feasible, can produce reliable results, and has the potential to characterize differences in risk between vaccine strains. The completion of this network by adding large reference hospitals, particularly from tropical countries, and the systematic WHO-led implementation of this approach, should permit the rapid post-marketing evaluation of safety signals for serious and rare adverse events for new and existing vaccines in all settings, including LMICs.
\end{abstract}

(c) 2017 World Health Organization. Published by Elsevier Ltd. All rights reserved.

Abbreviations: AEFI, adverse events following immunization; AM, aseptic meningitis; CI, Confidence Interval; CSF, cerebrospinal fluid; EMC, Erasmus Medical Center; FDA,

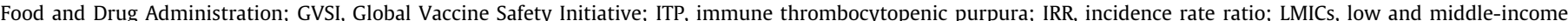

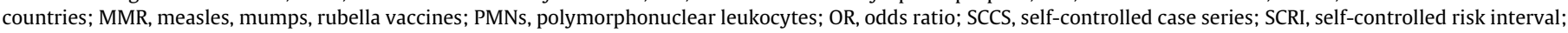
WHO, World Health Organization.

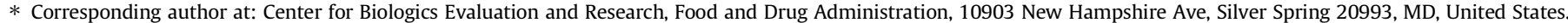

E-mail address: silvia.perezvilar@fda.hhs.gov (S. Perez-Vilar).

${ }^{1}$ See complete list of the WHO Global Vaccine Safety-Multi Country Collaboration co-authors in the online version. 


\section{Introduction}

With increasing number of vaccine products available, expansion of vaccine manufacturing capabilities, and availability of new vaccines targeted against diseases highly prevalent in low and middle-income countries (LMICs) [1], there is a need to enhance vaccine pharmacovigilance infrastructures globally [2]. Many countries do not have technical capacity and/or large enough populations to permit the evaluation of rare adverse events following immunization (AEFI) [2,3]. Enhancement of vaccine pharmacovigilance capabilities is a key activity for the World Health Organization (WHO) Global Vaccine Safety Initiative (GVSI) [4-6]. A previous international pilot study sponsored by WHO and the Food and Drug Administration (FDA), to evaluate the safety of the 2009-10 pandemic influenza vaccine, demonstrated that multinational hospital-based vaccine safety studies were feasible and could provide a useful framework for the evaluation of safety concerns [7]. Optimization of operational models, centralization of case adjudication, improvements in data quality control, closer supervision of data abstraction, and demonstration of the feasibility of such international collaborations, with high participation from LMICs, were identified by WHO as issues to be resolved [7]. Thus, for a subsequent demonstration project, it was important to reach higher participation from LMICs, select a vaccine widely used, and an AEFI that, at least in severe cases, would require hospitalization [2]. It was also essential to select an AEFI known to be associated with some of the vaccine strains being used.

Measles-containing vaccines are live-attenuated, often given in combination with mumps and rubella vaccines. The first dose is usually given at one year of age, although it is administered at nine months of age in countries with ongoing measles transmission [8]. The second dose is either given at 15-18 months of age, at 46 years of age, or in campaigns. Our objective was to demonstrate feasibility of an international hospital-based network for assessing epidemiological associations between serious and rare adverse events and vaccines in any setting, including LMICs. Two wellestablished associations were chosen: risk of aseptic meningitis (AM) following first dose of mumps-containing vaccines [9-11], and risk of immune thrombocytopenic purpura (ITP) following first dose of measles-containing vaccines [8,12-14].

\section{Methods}

International hospital-based retrospective observational study conducted as proof-of-concept for the investigation of rare AEFI using two analytical case-only methods: self-controlled risk interval (SCRI) and case-crossover [15,16]. For this purpose, WHO selected 26 sentinel sites ( 49 hospitals) distributed in 16 countries of the six WHO regions (Fig. 1). Selection criteria and capability assessments are described elsewhere (Bravo-Alcántara P, PerezVilar S, Molina-León HF et al. (accepted for publication in Vaccine [45])).

\subsection{Study population}

The study population included children ages 9-23 months admitted to a network-participating hospital during January 2010-March 2014, with a discharge diagnosis of either AM or ITP. Only individuals living in the pre-defined catchment area of the hospital, or, for those hospitals without a pre-specified catchment area, in the same city in which the hospital was located, were eligible.

\subsection{Case ascertainment and classification}

Participating hospitals identified potential cases through hospital discharge databases using pre-specified ICD-9/ICD-10 codes (Supplementary material; Table S-1) whereas hospitals not using a discharge codification system or not having electronic databases used free text. A trained physician or nurse blinded to vaccination status reviewed medical records of potential cases according to established case definitions (Supplementary material; Tables S-2 and S-3). Potential cases for which medical records were not available were excluded. Only first episodes of AM or ITP were considered.

Potential AM cases were excluded if they met criteria for encephalitis [17] (Supplementary material; Table S-4), the medical records showed that a physician ruled out a diagnosis of AM, a meningitis pathogen other than mumps virus was identified in cerebrospinal fluid (CSF), CSF protein concentration (in absence of traumatic lumbar puncture or intracerebral event) was $\geq 50 \mathrm{mg} / \mathrm{dL}$ with $\geq 10$ leukocytes $/ \mathrm{mm}^{3}$ and glucose $\leq 40 \mathrm{mg} / \mathrm{dL}$ in CSF, or if polymorphonuclear leukocytes (PMNs) in the CSF were $>1000 / \mathrm{mm}^{3}$ with glucose $\leq 40 \mathrm{mg} / \mathrm{dL}$ (modified from Lussiana et al.) [18].

Potential ITP cases were excluded if classified as chronic (defined as lasting $>6$ months) [12,14], with onset of symptoms occurring $>42$ days prior to hospital admission, or if a physician diagnosis in the medical records ruled out the diagnosis of ITP or thrombocytopenia. ITP cases with medical conditions associated with higher ITP risk (congenital/hereditary thrombocytopenia, aplastic anemia, defibrination syndrome, acquired hemolytic anemia, chronic liver disease, malignancy, or drug-induced thrombocytopenia) were also excluded. For the analyses presented here, patients treated with platelet-depleting medications (amiodarone, heparin, carbamazepine, phenytoin, valproic acid, quinidine, quinine, rifampicin, ethambutol, sulfisoxazole, vancomycin, ampicillin, trimethoprim-sulfamethoxazole, naproxen, or ranitidine) during hospitalization or in the 42 days prior, unless there was evidence that the drug was administered after disease onset date, were also excluded.

All cases were classified as either confirmed (Level 1-3 of diagnosis certainty) or non-confirmed (Supplementary material; Tables S-2 and S-3). Only confirmed cases entered the analyses.

The event date for AM cases was onset date of signs and symptoms suggestive of meningitis, admission date, or date of first physician diagnosis, whichever occurred earlier. The event date for ITP cases was onset date of spontaneous bleeding [19], date of first laboratory result with a platelet count $<50,000 / \mu \mathrm{L}$ performed within 42 days prior to hospital admission or during hospitalization, admission date, or date of first physician diagnosis, whichever occurred earlier.

\subsection{Vaccination status}

Vaccination status was retrieved, for confirmed cases only, from vaccine registries, vaccination cards, and medical records. The exposure of interest was first dose of measles/mumps-containing vaccine. Patients were considered as non-vaccinated when any other vaccinations, but not measles-containing vaccines, were registered in the consulted sources. Individuals without any vaccination record were excluded from the study.

\subsection{Data collection and sharing}

Sites collected data using a common protocol, and transferred them into electronic case report forms using the purpose-built 


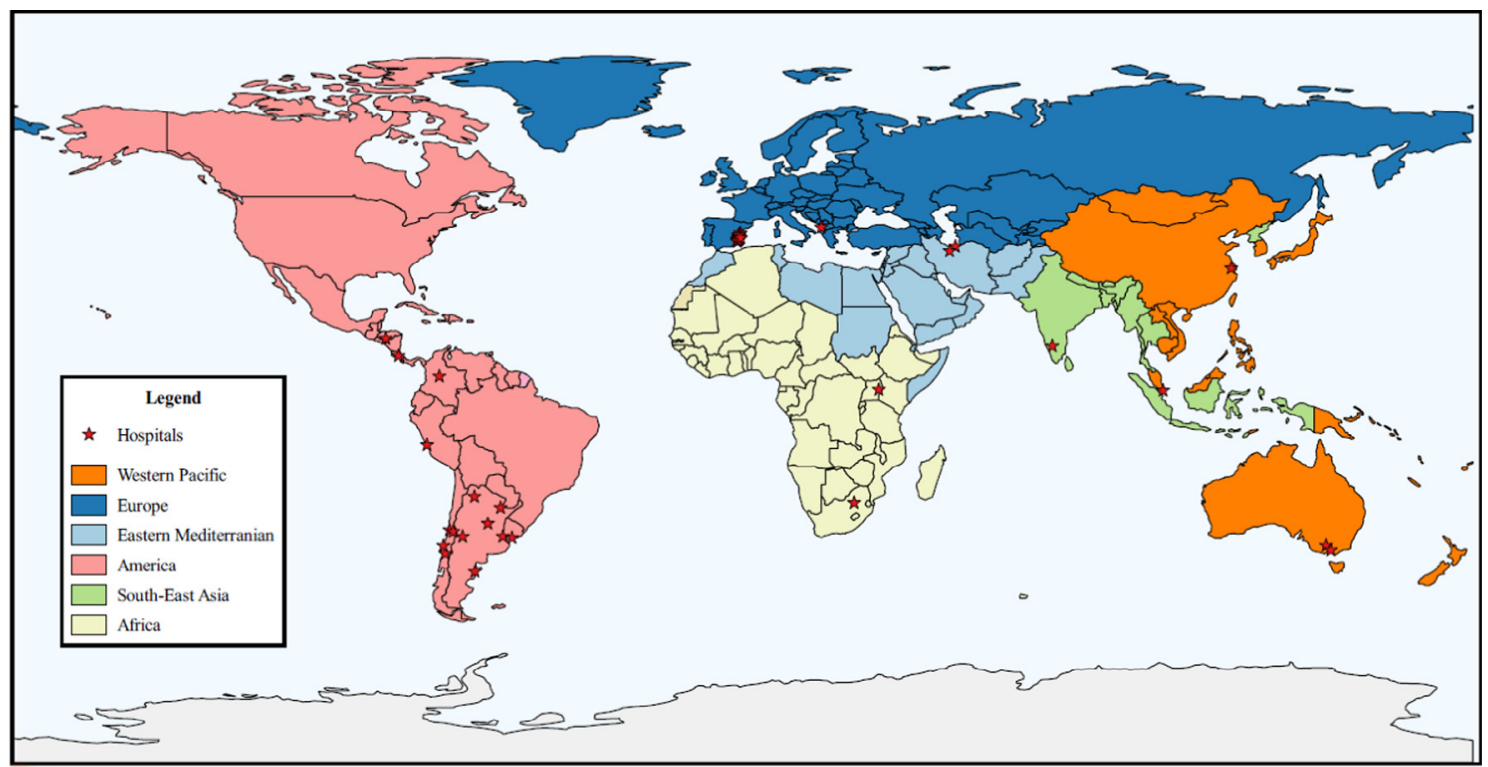

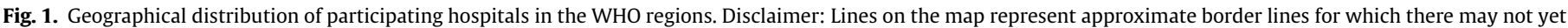
be full agreement.

Chameleon ${ }^{\circledR}$ system (Erasmus Medical Center (EMC), The Netherlands). Chameleon ${ }^{\circledR}$ classified the cases automatically according to their level of diagnostic certainty. Outcome and exposurecoded datasets containing non-identifiable time interval-only data created by Chameleon ${ }^{\circledR}$ were uploaded to a central remote research environment, located at EMC, through a secure connection.

\subsection{Quality assurance}

In parallel with the study protocol and manual of procedures, a quality assurance plan was developed. It included roles and responsibilities for feasibility assessment, protocol development, data collection/transformation, analysis and reporting. The coordination team trained investigators through on-site and/or virtual meetings and through a simulation exercise using dummy cases, reviewed data submitted using standardized procedures, and sent reports to the sites detailing inconsistencies and missing data found. Following these communications, sites were asked to submit final data for analyses. Detailed information on quality assurance activities implemented and operating procedures followed for data collection, entry, and submission can be found elsewhere
(Bravo-Alcántara P, Perez-Vilar S, Molina-León HF et al. (accepted for publication in Vaccine [45])).

\subsection{Statistical analyses}

The risks of AM following mumps-containing vaccination and ITP following measles-containing vaccination were estimated using self-controlled risk interval (SCRI) analyses [15,20,21]. The observation period started on the day following first-dose vaccination and ended on day 84 post-vaccination. Days 8-35 were considered the risk period, days $1-7$ and $36-42$ washout periods, and days 43-84 the non-risk period. Thus, only vaccinated cases for which the event occurred within 84 days following vaccination were included. Poisson regression conditioned on the fact that the event occurred was used to estimate the incidence rate ratio. Differential risk of AM and ITP in the risk and non-risk windows due to circulation of wild viruses linked to the diseases of interest and age were adjusted for in the models as follows: (1) cut-off points for seasonality were March 31, June 30, September 30, and December 31 ; (2) age was controlled for with periods ending at $365,457,549,641$ days, and 732 days of age.

Table 1

Measles and mumps strains included in the vaccine products used by the participating countries during the study period.

\begin{tabular}{|c|c|c|}
\hline Vaccine product & Measles strain & Mumps strain \\
\hline Priorix $^{\circledR}$, GlaxoSmithKline Biologicals & Schwarz & RIT $4385^{\mathrm{a}}$ \\
\hline Priorix Tetra ${ }^{\circledR}$, GlaxoSmithKline Biologicals & Schwarz & RIT $4385^{\mathrm{a}}$ \\
\hline MMR, Shanghai Institute of Biological Products, Co., Ltd & Shanghai-191 & S79 \\
\hline Measles, Lanzhou Institute of Biological Products Co., Ltd & Shanghai-191 & - \\
\hline Measles-Rubella, Beijing Tiantan Biological Products, Co., Ltd & Shanghai-191 & - \\
\hline M-M-R-II ${ }^{\circledR}$, Merck Sharp \& Dohme Corp. & Enders' Edmonston & Jeryl Lynn (Level B) \\
\hline MMR, Razi Vaccine and Serum Research Institute & AIK-C & Hoshino \\
\hline M-M-RVAXPRO ${ }^{\circledR}$, Sanofi Pasteur-MSD & Enders'Edmonston & Jeryl Lynn (Level B) \\
\hline Trimovax $^{\circledR}$, Sanofi Pasteur & Schwarz & Urabe Am9 \\
\hline Measles, Serum Institute of India Pvt. Ltd & Edmonston-Zagreb & - \\
\hline Measles-Rubella, Serum Institute of India Pvt. Ltd & Edmonston-Zagreb & - \\
\hline MMR, Serum Institute of India Pvt. Ltd & Edmonston-Zagreb & Leningrad-Zagreb \\
\hline Tresivac $^{\circledR}$, Serum Institute of India Pvt. Ltd & Edmonston-Zagreb & Leningrad-Zagreb \\
\hline Rouvax $^{\circledR}$, Sanofi Pasteur & Schwarz & - \\
\hline
\end{tabular}

Abbreviations: MMR (measles-mumps-rubella).

a Derived from Jeryl Lynn strain. 
Table 2

Characteristics of participating sentinel sites.

\begin{tabular}{|c|c|c|c|c|c|c|c|c|c|c|c|c|c|c|c|c|}
\hline \multirow[t]{2}{*}{ Site $^{\mathrm{a}}$} & \multirow{2}{*}{$\begin{array}{l}\text { Beds } \\
\text { (n) }\end{array}$} & \multicolumn{2}{|c|}{ Case ascertainment } & \multicolumn{4}{|c|}{ Vaccination status ascertainment } & \multicolumn{3}{|c|}{ Common outcome-exposure identifier } & \multicolumn{3}{|c|}{$\begin{array}{l}\text { Confirmed aseptic } \\
\text { meningitis cases }^{b}\end{array}$} & \multicolumn{3}{|c|}{ Confirmed ITP cases $^{\mathrm{b}}$} \\
\hline & & $\begin{array}{l}\text { ICD } \\
\text { codes }\end{array}$ & $\begin{array}{l}\text { Free } \\
\text { text }\end{array}$ & $\begin{array}{l}\text { Electronic } \\
\text { vaccine registry }\end{array}$ & $\begin{array}{l}\text { Vaccination } \\
\text { cards }\end{array}$ & $\begin{array}{l}\text { Medical } \\
\text { records }\end{array}$ & $\begin{array}{l}\text { Parents } \\
\text { contacted }^{\mathrm{c}}\end{array}$ & $\begin{array}{l}\text { Unique } \\
\text { identification } \\
\text { number }\end{array}$ & $\begin{array}{l}\text { Clinical history } \\
\text { number }\end{array}$ & $\begin{array}{l}\text { National } \\
\text { identity card }\end{array}$ & $\begin{array}{l}\text { Level } 1 \\
(\mathrm{n})\end{array}$ & $\begin{array}{l}\text { Level } 2 \\
\text { (n) }\end{array}$ & $\begin{array}{l}\text { Level } 3 \\
\text { (n) }\end{array}$ & $\begin{array}{l}\text { Level } 1 \\
\text { (n) }\end{array}$ & $\begin{array}{l}\text { Level } 2 \\
\text { (n) }\end{array}$ & $\begin{array}{l}\text { Level } 3 \\
\text { (n) }\end{array}$ \\
\hline Albania & 240 & ICD-9 & - & $\nu$ & $\boldsymbol{r}$ & - & - & - & $\boldsymbol{r}$ & - & 1 & - & - & 5 & - & - \\
\hline Argentina-01 & 330 & ICD-10 & - & $\nu$ & - & - & $r$ & - & $\boldsymbol{r}$ & $r$ & 1 & - & - & 6 & - & 1 \\
\hline Argentina-02 & 78 & ICD-10 & - & $r$ & - & - & $r$ & - & $r$ & $r$ & - & - & - & 1 & - & - \\
\hline Argentina-03 & 380 & ICD-10 & - & $r$ & - & $r$ & $r$ & - & $r$ & $r$ & - & - & - & 4 & - & - \\
\hline Argentina-04 & 246 & ICD-10 & - & $r$ & - & - & - & - & $r$ & $r$ & - & - & - & - & - & - \\
\hline Argentina-05 & 224 & ICD-10 & - & $r$ & - & - & - & - & $\nu$ & $r$ & - & - & - & 4 & - & - \\
\hline Argentina-06 & 61 & ICD-10 & - & $\nu$ & - & - & $r$ & - & $\nu$ & $\nu$ & - & - & - & 2 & - & - \\
\hline Australia-01 & 334 & ICD-10 & - & $\nu$ & - & - & - & $r$ & $r$ & - & 2 & 5 & - & 5 & - & 2 \\
\hline Australia-02 & 184 & ICD-10 & - & $\boldsymbol{r}$ & $r$ & - & - & $r$ & $r$ & - & - & - & 1 & 4 & - & - \\
\hline Chile-01 & 440 & ICD-10 & - & $r$ & - & - & - & - & - & $r$ & 3 & - & - & 2 & - & - \\
\hline Chile-02 & 300 & ICD-10 & - & $\nu$ & - & - & $r$ & - & - & $\nu$ & 5 & - & 1 & 4 & - & - \\
\hline Chile-03 & 704 & ICD-10 & - & $r$ & - & - & - & - & - & $r$ & - & - & - & 6 & - & - \\
\hline Chile-04 & 876 & ICD-10 & - & $r$ & - & - & $\nu$ & - & - & $r$ & - & 1 & - & 5 & - & - \\
\hline China & $500+$ & ICD-10 & - & $\boldsymbol{r}$ & - & - & - & - & - & - & - & - & 1 & 7 & - & - \\
\hline Colombia & 340 & ICD-10 & - & $\nu$ & - & - & - & - & - & $r$ & - & - & - & 2 & - & - \\
\hline Costa Rica & 313 & ICD-10 & - & $\boldsymbol{r}$ & - & - & $r$ & - & - & $r$ & 1 & 2 & 1 & 13 & - & - \\
\hline Honduras & 1109 & ICD-10 & - & - & - & $r$ & $r$ & - & $r$ & $r$ & - & - & - & 1 & - & - \\
\hline India & 1200 & ICD-9, ICD-10 & - & - & - & $r$ & $\boldsymbol{r}$ & $r$ & - & - & 3 & 5 & - & 1 & 1 & - \\
\hline Iran-01 & 246 & ICD-10 & - & - & - & $\nu$ & - & - & - & - & 8 & 16 & 2 & 14 & 3 & - \\
\hline Iran-02 & 340 & ICD-10 & - & - & - & $r$ & $r$ & - & - & - & 9 & 6 & 1 & 20 & - & - \\
\hline Peru & 465 & ICD-10 & - & - & - & $r$ & $\boldsymbol{r}$ & - & - & $\boldsymbol{r}$ & - & - & - & 7 & - & - \\
\hline Singapore & 830 & ICD-9, ICD-10 & - & $r$ & - & $r$ & - & $r$ & $r$ & $r$ & - & - & - & 17 & 1 & 2 \\
\hline South Africa & 3200 & ICD-10 & - & - & - & $r$ & $r$ & - & - & - & - & 1 & 2 & - & - & - \\
\hline Spain $^{\mathrm{d}}$ & 10,987 & ICD-9 & - & $r$ & - & - & - & $r$ & - & - & 2 & - & 3 & 32 & 2 & 6 \\
\hline Uganda & 254 & - & $r$ & - & $r$ & $r$ & $\nu$ & - & - & - & - & - & - & - & - & - \\
\hline Uruguay & 245 & ICD-10 & - & $r$ & - & - & - & - & - & $r$ & 1 & - & - & 3 & - & - \\
\hline
\end{tabular}

a The study period was January 2010 to March 2014, except for Australia, which retrospectively included the first 25 most recent cases that fulfill inclusion criteria for each condition (for both sites combined).

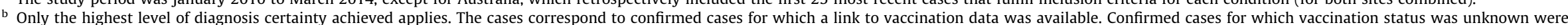
Only the highest level of

c Parents contacted were asked to provide a copy of the vaccination cards.

Spain was designated as one site, but included all public hospitals of the Valencia Region, its hospital beds correspond to the total number of beds from the combined hospitals. 
Per protocol, a case-crossover design was chosen as secondary analysis [22]. The observation period was 84 days prior to event occurrence (case window: days -1 to -42 ; control window: days -43 to -84$)$. Thus, cases without at least 84 days of follow-up prior to the event were excluded, regardless of vaccination status. The risk periods were days -8 to -35 for the case window and days -50 to -77 for the control window. The remaining periods were considered washout periods. Crude odds ratios were estimated using conditional logistic regression.

One site did not collect complete vaccination dates for any of the confirmed cases; thus, the day of vaccination was randomly imputed by Chameleon ${ }^{\circledR}$ within the month and year provided. Because of the importance of having exact vaccination dates for case-only methods, analyses with and without cases from this site (Iran-01) were performed.

Because the risks for AM and ITP may vary by virus strain, [811,23-25], exploratory analyses were performed by mumps and measles strain received, respectively. The two participating Iranian sites reported that three measles-mumps-rubella (MMR) vaccines, manufactured by Razi Vaccine, Serum Institute of India and Sanofi Pasteur, were used in the country during the study period, but they could not identify which specific product was administered to an individual patient. Thus, a separate analysis for the two Iranian sites was also conducted. Measles/mumps strains included in the vaccine products used by participating countries are shown in Table 1.

All analyses were conducted using SAS 9.4 (SAS Institute, Inc., Cary, NC). The WHO Ethics Review Committee and all local Ethics Committees approved the study and provided a waiver of informed consent according to article 32 of the Declaration of Helsinki [26]. Given the need for accurate information on vaccination status, a waiver to contact parents or legal representatives in case of lack of vaccination information was also obtained.

\section{Results}

A total of 84 confirmed AM cases and 183 confirmed ITP cases were eligible for inclusion in the case-only analyses. Number of confirmed cases successfully linked to vaccination records by site/country, level of diagnosis certainty, and site characteristics, including case ascertainment methods, vaccination data sources, and identifiers used to link exposures and outcomes, are shown in Table 2.

Among 84 AM cases, 80 (95\%) received a first dose of mumpscontaining vaccines (Table 3). A total of 51 (61\%) and a total of 73 (87\%) were eligible for inclusion in the SCRI and casecrossover analyses, respectively. The risk of AM following mumps containing vaccines was 10.9 (95\% CI 4.2-27.8) with the SCRI analysis. Sensitivity analyses excluding Iran-01 resulted in an IRR estimate of 11.7 (95\% CI 3.5-39.3). Intervals between first dose of mumps-containing vaccine and aseptic meningitis onset for cases included in the strain-specific SCRI analyses are shown in Fig. 2a. A significantly increased AM risk was found for the LeningradZagreb mumps strain (IRR: 10.8; 95\% CI: 1.3-87.4). Risk estimates for S79, UrabeAm9 and RIT 4385/Jeryl-Lynn strains could not be assessed given small numbers. For the vaccine products used in Iran (Hoshino/Leningrad-Zagreb/UrabeAm9), an IRR of 20.3 (95\% CI: 4.8-85.2) was identified (Table 4). Case-crossover analysis produced an overall unadjusted OR of 35.0 (95\% CI: 4.8-255.5). When cases from Iran-01 were excluded, the OR estimate was 22.0 (95\% CI: 3.0-163.2).

Among 183 ITP cases, 172 (94\%) were vaccinated with first dose of measles-containing vaccines. Of them, 55 (30\%) and 152 (83\%) were eligible for inclusion in the SCRI and case-crossover analyses, respectively. The risk of ITP following measles vaccination was 5.0
Table 3

Characteristics of children with confirmed aseptic meningitis or immune thrombocytopenic purpura (ITP).

\begin{tabular}{|c|c|c|}
\hline Characteristic & $\begin{array}{l}\text { Confirmed aseptic } \\
\text { meningitis cases } n=84\end{array}$ & $\begin{array}{l}\text { Confirmed ITP } \\
\text { cases } n=183\end{array}$ \\
\hline Male sex (n, \%) & $54(64 \%)$ & $98(54 \%)$ \\
\hline $\begin{array}{l}\text { Age at onset in months } \\
\text { (median; IQR) }\end{array}$ & $13(12-15)$ & $15(12-19)$ \\
\hline $\begin{array}{l}\text { Mumps-containing first dose } \\
\text { vaccination }(n, \%)\end{array}$ & $80(95 \%)$ & - \\
\hline Exact date known (n, \%) & $60(75 \%)$ & - \\
\hline Vaccine brand known (n, \%) & $41(51 \%)$ & - \\
\hline $\begin{array}{l}\text { Age at vaccination in months } \\
\text { (median; IQR) }\end{array}$ & $12(11-12.5)$ & - \\
\hline $\begin{array}{l}\text { Measles-containing first } \\
\text { dose vaccination }(\mathrm{n}, \%)\end{array}$ & - & $172(94 \%)$ \\
\hline Exact date known $(\mathrm{n}, \%)$ & - & $159(92 \%)$ \\
\hline Vaccine brand known (n, \%) & - & $125(73 \%)$ \\
\hline $\begin{array}{l}\text { Age at vaccination in months } \\
\text { (median; IQR) }\end{array}$ & - & $12(12-15)$ \\
\hline
\end{tabular}

Two aseptic meningitis cases died during the observation period, one case in Spain 78 days after disease onset date and another case in Australia 608 days following disease onset. None ITP case was known to die during the observation period.

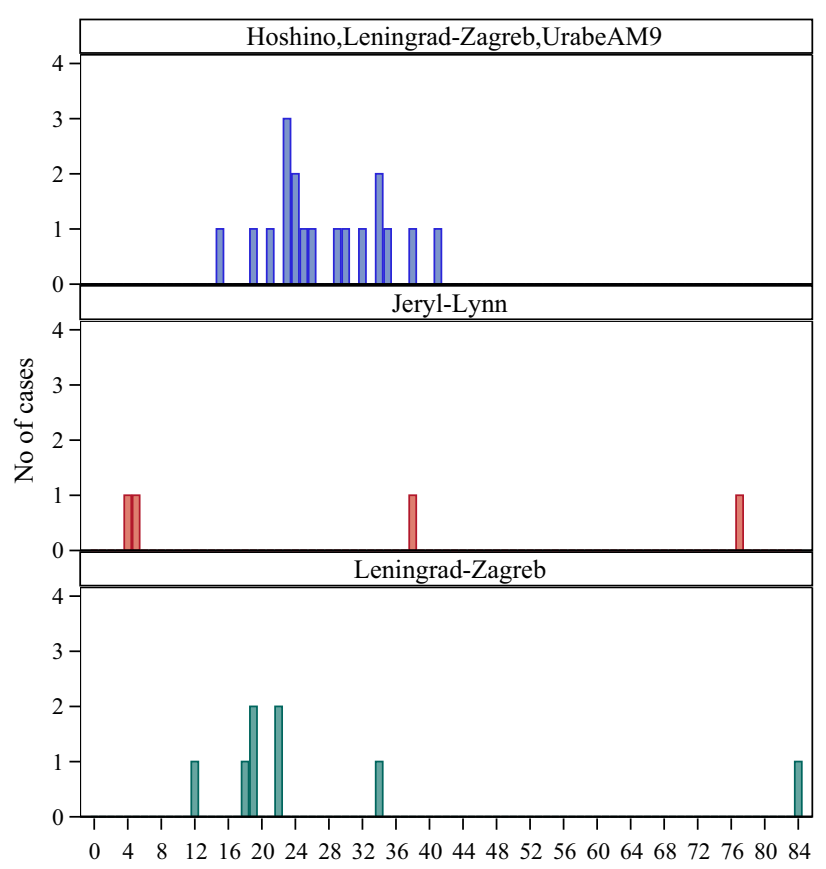

Interval (days) from first dose vaccination to Aseptic Meningitis onset

Fig. 2a. Interval between first dose of mumps-containing vaccines and aseptic meningitis onset by mumps vaccine strain. Only aseptic meningitis cases with onset on days 0 to 84 are shown. Cases from Iran01 for which exact vaccination dates were unavailable were excluded. Mumps strain used in the Iranian sites was either Hoshino, Urabe Am9 or Leningrad-Zagreb.

(95\% CI: 2.5-9.7); exclusion of cases from Iran-01 resulted in an IRR estimate of 7.7 (95\% CI: 3.5-17.3). Intervals between first dose of measles-containing vaccine and ITP onset for cases included in the strain-specific SCRI analyses are shown in Fig. 2b. This analysis showed a significantly elevated ITP risk for measles vaccines containing Schwarz (IRR: 20.7; 95\% CI: 2.7-157.6), EdmonstonZagreb (IRR: 11.1; 95\% CI: 1.4-90.3), and Enders'Edmonston (IRR: 8.5; 95\% CI: 1.9-38.1) strains. Risk estimates for Shanghai-191 could not be assessed because of small numbers. Our estimates for the vaccine product/s used in Iran (AIK-C/Edmoston-Zagreb/ Schwarz) did not show an increased risk of ITP (IRR: $0.51 ; 95 \%$ CI: 0.10-2.54) (Table 4). The case-crossover analysis produced an 
Table 4

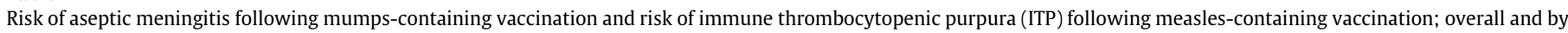
vaccine strain.

\begin{tabular}{|c|c|c|c|c|c|}
\hline \multirow[t]{3}{*}{ Mumps vaccine strain ${ }^{a}$} & \multicolumn{5}{|l|}{ SCRI analyses } \\
\hline & \multirow[t]{2}{*}{$\begin{array}{l}\text { Event in risk period } \\
\text { ( } 8-35 \text { days) }\end{array}$} & \multirow[t]{2}{*}{$\begin{array}{l}\text { Event in non-risk period } \\
\text { ( } 43-84 \text { days) }\end{array}$} & \multirow{2}{*}{$\begin{array}{l}\text { Median (P25-P75) } \\
\text { Follow-up (days) }\end{array}$} & Unadjusted (95\% CI) & Adjusted 95\% CI \\
\hline & & & & \multicolumn{2}{|l|}{ Relative incidence (IRR) } \\
\hline & \multicolumn{5}{|c|}{ Eligible confirmed aseptic meningitis cases ${ }^{\mathrm{b}}$} \\
\hline Overall & 35 & 5 & $85(85,85)$ & $10.9(4.2-27.8)$ & $10.8(4.0-29.2)$ \\
\hline Overall $^{\mathrm{c}}$ & 22 & 3 & $85(85,85)$ & $11.7(3.5-39.3)$ & $12.4(3.1-49.1)$ \\
\hline Hoshino/Leningrad-Zagreb/UrabeAm9 & 27 & 2 & $85(85,85)$ & $20.3(4.8-85.2)$ & Non-estimable \\
\hline Hoshino/Leningrad-Zagreb/UrabeAm9 ${ }^{c}$ & 14 & 0 & $85(85,85)$ & Non-estimable & Non-estimable \\
\hline Leningrad-Zagreb & 7 & 1 & $85(85,85)$ & $10.8(1.3-87.4)$ & $6.4(0.3-124.4)$ \\
\hline \multirow[t]{2}{*}{ RIT 4385/Jeryl Lynn (Level B) } & 0 & 1 & $85(85,85)$ & Non-estimable & Non-estimable \\
\hline & \multicolumn{5}{|c|}{ Eligible confirmed ITP cases ${ }^{\mathrm{b}}$} \\
\hline Overall & 36 & 12 & $85(70,85)$ & $5.0(2.5-9.7)$ & $5.6(2.7-11.9)$ \\
\hline Overall $^{\mathrm{C}}$ & 36 & 8 & $85(70,85)$ & $7.7(3.5-17.3)$ & $9.1(3.7-22.3)$ \\
\hline AIK-C/ Edmonston-Zagreb /Schwarz & 2 & 5 & $85(85,85)$ & $0.51(0.10-2.54)$ & $0.54(0.08-3.55)$ \\
\hline Edmonston-Zagreb & 7 & 1 & $85(67,85)$ & $11.1(1.4-90.3)$ & $8.4(0.7-100.3)$ \\
\hline Enders'Edmonston & 11 & 3 & $85(43,85)$ & $8.5(1.9-38.1)$ & $28.7(1.9-443.5)$ \\
\hline Schwarz & 14 & 1 & $85(76,85)$ & $20.7(2.7-157.6)$ & Non-estimable \\
\hline Shanghai-191 & 0 & 1 & $85(85,85)$ & Non-estimable & Non-estimable \\
\hline
\end{tabular}

a There were no cases within days 8-35 or days 43-84 following first dose vaccination with mumps strains S79 or Urabe Am9.

b The remaining cases occurred during the washout periods (days 1-7, days 36-42 following vaccination).

c Excluding cases from Iran-01 since this site did not provide exact vaccination dates.

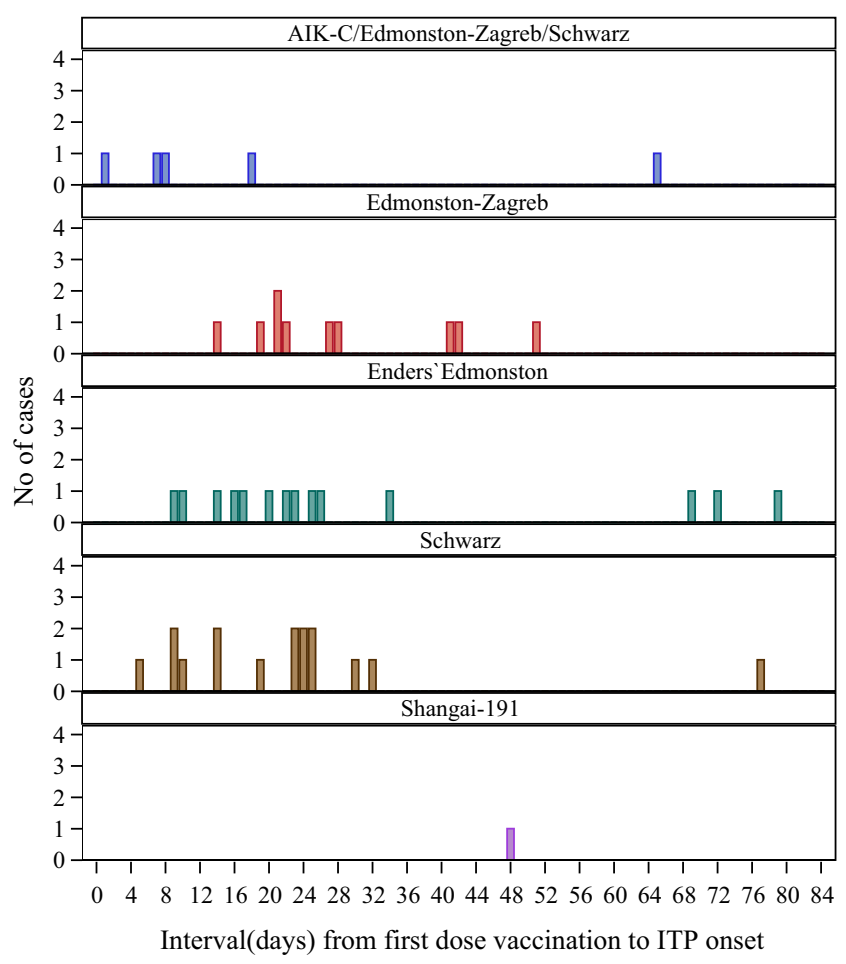

Fig. 2b. Interval between first dose of measles-containing vaccines and immune thrombocytopenic purpura) ITP onset by measles vaccine strain. Only ITP cases which onset on days 0-84 days are shown. Cases from Iran01 for which vaccination dates were imputed were excluded. Cases that received platelet depleting medication were excluded.

overall unadjusted OR of 4.7 (95\% CI: 2.1-10.7). When cases from Iran-01 were excluded, the OR estimate was 6.6 (95\% CI: 2.6-16.9).

\section{Discussion}

The success of this proof-of-concept study in obtaining participation and data useful for analysis from sites located in all regions of the world using a common protocol has demonstrated the feasibility of international collaborative hospital-based studies, with high participation of LMICs, for the investigation of serious and rare AEFI. Moreover, the study has confirmed increased risks of AM following first dose of mumps-containing vaccines, and of ITP following first dose of measles-containing vaccines. It has also shown, potential risk differences between vaccine strains for both associations. The elevated risk estimates found for the LeningradZagreb mumps strain are consistent with previous studies $[27,28]$. Regarding Jeryl-Lynn-derived strain vaccines, although the study did not have enough power to confirm the absence of risk for these strains, our finding of zero cases in the risk window was consistent with the hypothesis of no association [25,29]. The two Iranian sites reported that three vaccine products, containing the mumps strains Hoshino, Leningrad-Zagreb and UrabeAm9 were used during the study period, but they did not differentiate between them. Therefore, we could not assign the high risk of AM identified in Iran to one or other of these three strains [23,24,27,28,30-32]. This would require further investigation in subsequent studies, particularly to determine the risk associated with the Hoshino strain, given the limited literature available on its safety profile [33-36]. AM usually occurs within 2-5 weeks following mumps vaccination $[9,11,31,32,37,38]$; therefore, our study used a risk window of 8-35 days post-vaccination. Our study found a statistically significant risk when the washout period (days 1-7 and days 36-42 post-vaccination) was compared to the non-risk periods (days $43-84$ post-vaccination) for the vaccine/s products used in Iran (IRR: 12.9; 95\% CI: 2.8-59.7), which suggests the possibility of an increased risk also for the washout period, that deserves investigation in future studies.

The elevated risk of ITP following measles-containing vaccination is consistent with the literature [12-14]. Our strain-specific unadjusted analysis showed a significantly elevated ITP risk for measles vaccines containing the Schwarz, Edmonston-Zagreb, and Enders'Edmonston strains. No risk of ITP was identified in Iran, which reported the concurrent distribution of three vaccine products including the AIK-C, Edmonston-Zagreb and Schwarz strains, without distinguishing between them. Among 172 vaccinees included in this study, at least 155 (90\%) received MMR or measles-rubella vaccines. Given the known association between wild rubella infection and ITP [39], and the existence of a few studies 
showing mostly mild thrombocytopenia following rubella vaccination in some adults [19,40-42], a potential contribution of the rubella component of the vaccine to our findings may not be excluded.

Case-only methods can be efficient epidemiological designs for use in vaccine safety, particularly for LMICs, given that population denominators or separate controls are not required; moreover, time-fixed confounders are inherently adjusted for [16]. Selfcontrolled case series (SCCS) methods have been successfully implemented in similar international collaborations, such as the hospital-based international collaborative investigation of Guillain-Barre syndrome following the H1N1 2009-2010 pandemic influenza vaccination [7], and the investigation of the association between intussusception and rotavirus in Mexico and Brazil [43]. In our study, some of the participating sites could not identify end of the follow-up period independently of the event being investigated, thus, modifying the duration of the observation period in ways that could potentially bias results [44]. The SCRI approach simplifies the SCCS design by reducing the length of the control interval [21]. The selection of shorter non-risk periods, as done in our study under the assumption that participants were not lost to follow-up during this 84-day period, not only may solve this limitation for LMICs, but may also decrease the effect of timevarying confounders on the risk estimates, because risk variations in such a short period may be negligible [21]. Nonetheless, adjustments for age group and seasonality were performed, when possible. For comparison purposes, we used case-crossover as a secondary analysis, given that it does not require follow-up after case occurrence; to decrease the possibility of bias associated with variations in the distributions of exposures over time, only one control window of the same duration as the case window was selected [16]. The method requires the same underlying probability of vaccination in all time intervals, which is unlikely to hold true for pediatric vaccines, which are usually administered according to pre-specified schedules [16]. However, our case-crossover unadjusted risk estimates for ITP following measles-containing vaccines and for AM following mumps-containing vaccines were comparable to those obtained using the SCRI method, although the latter estimate was less stable due to limited study power.

Case-only methods demand careful determination of event onset and vaccination dates. Therefore, we were particularly thorough in training site investigators. Given that one site could not provide exact vaccination dates (only month/year of vaccination were recorded), we performed analyses both excluding and including this site (using imputed dates for the site). Although these analyses showed differences in point estimates, all results were significant and the confidence intervals overlapped. Since SCRI uses data only from vaccinees, the approach minimizes potential misclassification due to incomplete/absent data on vaccination status, another frequent shortcoming in LMICs. Nonetheless, a possible limitation in the approach used here is that site variability may be a potential source of selection bias as the sites may have differences in access to vaccination records and in patient's health-seeking behavior. Bias could also be associated with site differences in diagnosis capabilities and quality of medical records. Also, our use of self-controlled analytical methods did not permit estimations of absolute risk [20].

Our results show that collaborative studies for the investigation of different vaccine products by strain and potentially by manufacturer are feasible. The power to do so, and to investigate risk by country/region (Supplementary material; Tables S-5 and S-6) will increase when additional large hospitals with medical specialties for rare and difficult to diagnose events, high quality medical records and easy access to vaccination records are included [2]. The inclusion of large referral hospitals with electronic discharge databases should decrease per case investigation costs by reducing efforts associated with data extraction, study coordination, training, data quality assessment, and provide quality medical records and higher reliability in disease codification. The use of large hospitals would also reduce the likelihood of having participating hospitals that do not contribute cases to the analysis, as has occurred in some of our sites. Because easy and unequivocal linkages between hospital and vaccination records and proven access to vaccination information would increase data quality and efficiency, it is important to carefully select the participating sites, particularly in LMICs. Given the current interest on the development of vaccines for diseases such as dengue, malaria, and Zika, prioritization should be given to the addition of sites from tropical/subtropical areas in LMICs for future studies.

\section{Conclusions}

This collaboration has demonstrated, for the first time, that a multi-country hospital-based network with high participation of LMICs, using a common protocol and standardized procedures, permits the investigation of rare vaccine adverse events, can produce reliable results, and has the potential to characterize risk differences between vaccine strains. The completion of this network with the addition of large referral hospitals, including from tropical/subtropical countries, and the systematic implementation of this hospital-based approach, should permit the rapid and sustainable evaluation of safety signals for serious and rare AEFI for new and existing vaccines in all settings, and the comparison of safety profiles for vaccine products.

\section{Funding}

Center for Biologics Evaluation and Research (CBER)-U.S. Food and Drug Administration (FDA) funded this project (Grant number U01 FD004575). GRiP, Global Research in Pediatrics, European Union Seventh framework Programme (FP7/2007-2013) provided additional funding under grant agreement $n^{\circ} 261060$.

\section{Conflicts of interest}

DW has received honoraria from GlaxoSmithKline Biologicals (GSK) for consultancies on malaria vaccine safety studies and implementation unrelated to the content of this manuscript. SB is a consultant for GSK. MS is heading a research group that conducts PASS studies for pharmaceutical companies including GSK.

All other authors confirm that there are no known conflicts of interest associated with this publication.

\section{Acknowledgements}

The authors thank Hector S. Izurieta for his valuable contributions to the conception of the project, Mees Mosseveld and Peter Rijnbeek for development of data collection and data sharing tools, Sergio Castillo-Pérez for mapping, and personnel from participating sentinel sites for facilitating the study implementation.

\section{Appendix A. Supplementary material}

Supplementary data associated with this article can be found, in the online version, at http://dx.doi.org/10.1016/j.vaccine.2017.05. 012.

\section{References}

[1] Gavi. The vaccine alliance 2017 [cited 2017 February 27]. Available from: http://www.gavi.org.

[2] Izurieta HS, Zuber P, Bonhoeffer J, Chen RT, Sankohg O, Laserson KF, et al. Roadmap for the international collaborative epidemiologic monitoring of 
safety and effectiveness of new high priority vaccines. Vaccine 2013;31 (35):3623-7.

[3] World Health Organization. Global vaccine safety blueprint. The landscape analysis. WHO/IVB/12.04: Quality, Safety, and Standards unit of the Department of Immunizations, Vaccines and Biologicals; 2012 [cited 2016 February, 7]. Available from: http://apps.who.int/iris/bitstream/10665/70854/ 1/WHO_IVB_12.04_eng.pdf.

[4] Amarasinghe A, Black S, Bonhoeffer J, Carvalho SM, Dodoo A, Eskola J, et al. Effective vaccine safety systems in all countries: a challenge for more equitable access to immunization. Vaccine 2013;31(Suppl 2):B108-14.

[5] 5. World Health Organization. Global vaccine safety blueprint. WHO/IVB/ 12.07: Quality, Safety, and Standards unit of the Department of Immunization, Vaccines and Biologicals; 2012 [cited 2016 February 7]. Available from: http:// extranet.who.int/iris/restricted/bitstream/10665/70919/1/ WHO_IVB_12.07_eng.pdf?ua=1.

[6] Maure CG, Dodoo AN, Bonhoeffer J, Zuber PL. The Global Vaccine Safety Initiative: enhancing vaccine pharmacovigilance capacity at country level. Bull World Health Organ 2014;92(9):695-6.

[7] Dodd CN, Romio SA, Black S, Vellozzi C, Andrews N, Sturkenboom M, et al. International collaboration to assess the risk of Guillain Barre Syndrome following Influenza A (H1N1) 2009 monovalent vaccines. Vaccine 2013;31 (40):4448-58.

[8] Measles vaccines: WHO position paper. Wkly Epidemiol Rec. 2009; 84(35): p. 349-60.

[9] Tapiainen T, Prevots R, Izurieta HS, Abramson J, Bilynsky R, Bonhoeffer J, et al. Aseptic meningitis: case definition and guidelines for collection, analysis and presentation of immunization safety data. Vaccine 2007;25(31):5793-802.

[10] Mumps virus vaccines. Wkly Epidemiol Rec. 2007;82(7):51-60.

[11] Bonnet MC, Dutta A, Weinberger C, Plotkin SA. Mumps vaccine virus strains and aseptic meningitis. Vaccine. 2006;24(49-50):7037-45.

[12] O'Leary ST, Glanz JM, McClure DL, Akhtar A, Daley MF, Nakasato C, et al. The risk of immune thrombocytopenic purpura after vaccination in children and adolescents. Pediatrics 2012;129(2):248-55.

[13] Mantadakis E, Farmaki E, Buchanan GR. Thrombocytopenic purpura after measles-mumps-rubella vaccination: a systematic review of the literature and guidance for management. J Pediatr 2010;156(4):623-8.

[14] France EK, Glanz J, Xu S, Hambidge S, Yamasaki K, Black SB, et al. Risk of immune thrombocytopenic purpura after measles-mumps-rubella immunization in children. Pediatrics 2008;121(3):e687-92.

[15] Maclure M, Fireman B, Nelson JC, Hua W, Shoaibi A, Paredes A, et al. When should case-only designs be used for safety monitoring of medical products? Pharmacoepidemiol Drug Saf 2012;21(Suppl 1):50-61.

[16] Farrington CP. Control without separate controls: evaluation of vaccine safety using case-only methods. Vaccine 2004;22(15-16):2064-70.

[17] Sejvar JJ, Kohl KS, Bilynsky R, Blumberg D, Cvetkovich T, Galama J, et al. Encephalitis, myelitis, and acute disseminated encephalomyelitis (ADEM): case definitions and guidelines for collection, analysis, and presentation of immunization safety data. Vaccine 2007;25(31):5771-92.

[18] Lussiana C, Loa Clemente SV, Pulido Tarquino IA, Paulo I. Predictors of bacterial meningitis in resource-limited contexts: an Angolan case. PLoS One 2011;6 (10):e25706.

[19] Wise RP, Bonhoeffer J, Beeler J, Donato H, Downie P, Matthews D, et al. Thrombocytopenia: case definition and guidelines for collection, analysis, and presentation of immunization safety data. Vaccine 2007;25(31):5717-24.

[20] Whitaker HJ, Farrington CP, Spiessens B, Musonda P. Tutorial in biostatistics: the self-controlled case series method. Stat Med 2006;25(10):1768-97.

[21] Li R, Stewart B, Weintraub E. Evaluating efficiency and statistical power of selfcontrolled case series and self-controlled risk interval designs in vaccine safety. J Biopharm Stat 2016;26(4):686-93.

[22] Maclure M, Mittleman MA. Should we use a case-crossover design? Annu Rev Public Health 2000;21:193-221.

[23] Ki M, Park T, Yi SG, Oh JK, Choi B. Risk analysis of aseptic meningitis after measles-mumps-rubella vaccination in Korean children by using a casecrossover design. Am J Epidemiol 2003;157(2):158-65.
[24] Fujinaga T, Motegi Y, Tamura H, Kuroume T. A prefecture-wide survey of mumps meningitis associated with measles, mumps and rubella vaccine. Pediatr Infect Dis J 1991;10(3):204-9.

[25] Black S, Shinefield H, Ray P, Lewis E, Chen R, Glasser J, et al. Risk of hospitalization because of aseptic meningitis after measles-mumps-rubella vaccination in one- to two-year-old children: an analysis of the Vaccine Safety Datalink (VSD) Project. Pediatr Infect Dis J 1997;16(5):500-3.

[26] World Medical A. World Medical Association Declaration of Helsinki: ethica principles for medical research involving human subjects. JAMA 2013;310 (20):2191-4.

[27] da Cunha SS, Rodrigues LC, Barreto ML, Dourado I. Outbreak of aseptic meningitis and mumps after mass vaccination with MMR vaccine using the Leningrad-Zagreb mumps strain. Vaccine 2002;20(7-8):1106-12.

[28] da Silveira CM, Kmetzsch CI, Mohrdieck R, Sperb AF, Prevots DR. The risk of aseptic meningitis associated with the Leningrad-Zagreb mumps vaccine strain following mass vaccination with measles-mumps-rubella vaccine, Rio Grande do Sul, Brazil, 1997. Int J Epidemiol 2002;31(5):978-82.

[29] Makela A, Nuorti JP, Peltola H. Neurologic disorders after measles-mumpsrubella vaccination. Pediatrics 2002;110(5):957-63.

[30] Dourado I, Cunha S, Teixeira MG, Farrington CP, Melo A, Lucena R, et al Outbreak of aseptic meningitis associated with mass vaccination with a urabecontaining measles-mumps-rubella vaccine: implications for immunization programs. Am J Epidemiol 2000;151(5):524-30.

[31] Sugiura A, Yamada A. Aseptic meningitis as a complication of mumps vaccination. Pediatr Infect Dis J 1991;10(3):209-13.

[32] Mumps meningitis and MMR vaccination. Lancet 1989; 2(8670): p. 1015-6

[33] Dorreh FHM. Adverse events associated with MMR vaccines in Arak. J Iranian Clin Res 2015;1:6-10.

[34] Esteghamati A, Keshtkar A, Heshmat R, Gouya MM, Salar Amoli M, Armin S, et al. Adverse reactions following immunization with MMR vaccine in children at selected provinces of Iran. Arch Iran Med 2011;14(2):91-5.

[35] Ueda K, Miyazaki C, Hidaka Y, Okada K, Kusuhara K, Kadoya R. Aseptic meningitis caused by measles-mumps-rubella vaccine in Japan. Lancet 1995;346(8976):701-2.

[36] Sood A, Mitra M, Joshi HA, Nayak US, Siddaiah P, Babu TR, et al. Immunogenicity and safety of a novel MMR vaccine (live, freeze-dried) containing the Edmonston-Zagreb measles strain, the Hoshino mumps strain, and the RA 27/3 rubella strain: Results of a randomized, comparative, active controlled phase III clinical trial. Hum Vaccin Immunother 2017: p. 1-8.

[37] Kimura M, Kuno-Sakai H, Yamazaki S, Yamada A, Hishiyama M, Kamiya H, et al. Adverse events associated with MMR vaccines in Japan. Acta Paediatr Jpn $1996 ; 38(3): 205-11$.

[38] Miller E, Andrews N, Stowe J, Grant A, Waight P, Taylor B. Risks of convulsion and aseptic meningitis following measles-mumps-rubella vaccination in the United Kingdom. Am J Epidemiol 2007;165(6):704-9.

[39] Toltzis P. 50 Years Ago in The Journal of Pediatrics: Some Recently Recognized Manifestations of the Rubella Syndrome. J Pediatr 2015;167(2):441.

[40] Forrest JM, Honeyman MC, Lovric VA. Rubella vaccination and thrombocytopenia. Aust N Z J Med 1974;4(4):352-5.

[41] Freestone DS, Prydie J, Smith SG, Laurence G. Vaccination of adults with Wistar RA 27/3 rubella vaccine. J Hyg (Lond) 1971;69(3):471-7.

[42] Bartos HR. Thrombocytopenia associated with rubella vaccination. N Y State J Med 1972;72(4):499.

[43] Patel MM, Lopez-Collada VR, Bulhoes MM, De Oliveira LH, Bautista Marquez A Flannery $\mathrm{B}$, et al. Intussusception risk and health benefits of rotavirus vaccination in Mexico and Brazil. N Engl J Med 2011;364(24):2283-92.

[44] Weldeselassie YG, Whitaker HJ, Farrington CP. Use of the self-controlled caseseries method in vaccine safety studies: review and recommendations for best practice. Epidemiol Infect 2011;139(12):1805-17.

[45] Bravo-Alcántara P, Pérez-Vilar S, Molina-León HF, Sturkenboom M, Black S Zuber PLF, et al. Building capacity for active surveillance of vaccine adverse events in the Americas: A hospital-based multi-country network. Vaccine 2018;36(3):363-70. 